\title{
UMA TÉCNICA, UM GRUPO E UMA RETÓRICA: \\ A GramÁtica Construtural NA HISTÓRIA DA \\ LINGUíSTICA BRASILEIRA
}

\author{
A technique, a group and a rethoric: \\ the Constructural Grammar in the \\ history of Brazilian linguistics
}

\author{
Ronaldo de Oliveira Batista*
}

\begin{abstract}
RESUMO
A partir de pressupostos teórico-metodológicos da Historiografia Linguística, este texto analisa um período específico da linguística brasileira, a década de 1970 e a proposição, por Eurico Back e Geraldo Mattos, de um projeto de investigação linguística reconhecido como Gramática Construtural. Observam-se a constituição de um grupo de especialidade e a formação de uma proposta de análise de dados da língua portuguesa em meio ao estabelecimento de uma retórica de ruptura, que procurou demarcar um espaço específico para a perspectiva construturalista em meio a outros projetos científicos.
\end{abstract}

Palavras-chave: Historiografia Linguística; Gramática Construtural; grupos de especialidade; programas de investigação.

\begin{abstract}
Based on theoretical and methodological assumptions of linguistic historiography, this article analyzes a specific period of the Brazilian linguistics, the nineteen seventies, and the proposition, by Eurico Back and Geraldo Mattos, of a research project known as linguistic Constructural Grammar. We observe the formation of a group of specialty and a proposal for data

* Universidade Presbiteriana Mackenzie
\end{abstract}


analysis for the Portuguese language in the midst of establishing a rhetoric of rupture, which sought to set the boundaries of a specific space for the constructuralist approach among other scientific projects.

Keywords: Linguistics Historiography; Constructural Grammar; specialty groups; research programs.

\title{
1. INTRODUÇÃo: CIENTIFICIDADE E DISCURSOS DE AFIRMAÇÃo OU NEGAÇÃo NA DÉCADA DE 1970
}

A linguística brasileira da década de 1970 e os recém-criados centros de pesquisa e ensino na área, diluídos em diferentes perspectivas de tratamento de dados e fenômenos linguísticos ${ }^{1}$, testemunharam o delineamento de um horizonte privilegiado para seu espaço de atuação social ${ }^{2}$, como nos indicam textos de divulgação de livros publicados no Brasil na época.

\begin{abstract}
É um livro objetivo e oportuno, nesta hora em que os estudos linguísticos estão em primeiro plano no Brasil. Constituindo uma rigorosa introdução aos problemas gerais da Linguística, esta obra vem enriquecer a bibliografia brasileira numa área de grande interesse [...] (Texto de orelha da ed. Brasileira, MALMBERG, 1976, grifo nosso).
\end{abstract}

O destaque hoje assumido pela Lingüística no campo das Ciências Humanas evidencia-se, quando mais não fosse, pelo número crescente de livros, publicações, cursos e programas de estudo a ela consagrados. [...] (Texto da quarta capa da ed. brasileira, DUBOIS et al., 1973, grifo nosso).

1 "A década de setenta seria marcada, pois, não só pela instalação no país dos primeiros cursos específicos de graduação e pós-graduação em Lingüística mas também pelo estabelecimento - ou questionamento - da profissão do lingüista; pela criação das primeiras associações nacionais e regionais; pela preocupação com a publicação periódica da produção acadêmico-científica; pelo desenvolvimento de projetos coletivos e pela formação de um setor editorial especializado" (ALTMAN, 1998, p. 167).

"A tônica do momento era a diversificação. A multiplicidade se refletiu, em primeiro lugar, nos tipos de artigos veiculados pelos periódicos. A proporção entre artigos programáticos - que propunham um 'novo' modelo ou um 'novo' tipo de investigação; artigos de crítica - que refutaram, total ou parcialmente análises já feitas e que, no lugar, propuseram outra; e artigos de pesquisa que simplesmente aplicavam um modelo, é bastante diferente na década de setenta, em relação às décadas de sessenta e oitenta [...]" (ALTMAN, 1998, p. 279)

2 Considera-se como "espaço social" de atuação a inserção que os linguistas tinham no cenário acadêmico de sua época, considerando sua filiação institucional e também o reconhecimento que advogavam, legitimando, assim, discursos produzidos a partir da dimensão discursiva em que se situavam. 
Outros exemplos dessa valorização na década de 1970: a coleção os pensadores, na sua formatação da época, trazia volume específico, de 1978, com textos de Saussure, Jakobson, Hjelmslev, Chomsky. Ao lado de Platão, Descartes, Hegel, Kant, um grupo de linguistas, então considerados fundamentais para uma abordagem da linguagem verbal; cerca de cinquenta anos após a edição do Curso de linguística geral em 1916, Isaac Nicolau Salum reconhecia na $1^{\text {a }}$. edição brasileira do Curso, em 1969, a dimensão dos estudos linguísticos: "já se tem dito, e com razão, que a Lingüística é hoje a 'vedete' das ciências humanas" (SALUM, 1993 p. XIV).

Nesse momento, havia uma ânsia pela atitude científica nas ciências humanas, liderada pela sua ciência-piloto, a linguística ("os anos setenta seriam dos lingüistas"3). Esse desejo não deixava de fazer eco a uma onda de ufanismo e crença que caracterizou a dinâmica social dos anos 1970, em muitos aspectos ancorada em uma imagem simbólica de avanço e progresso que se construiu em diferentes esferas da sociedade. Se o caminho era avante Brasil, o pensamento intelectual do momento também nos levava à construção ou à recepção de novas possibilidades de obtenção de saberes e conhecimento (cf. MOTOYAMA; QUEIROZ; VARGAS, 2004, p. 327; ORTIZ, 2006, p. 81; PILAGALLO, 2009, p. 79).

Em meio a empreendimentos para expansão de pesquisas em setores tradicionais, como ciências naturais e exatas, a linguagem humana passava cada vez mais a ser objeto de novas formas de análise e descrição. A proposta da linguística e os discursos dos linguistas ganhavam destaque e pareciam, de fato, conduzir o conjunto de saberes sobre as línguas a um patamar distinto daquele conhecido no Brasil até então ${ }^{4}$.

No entanto, em âmbito social e intelectual mais geral, a percepção do que faziam os linguistas estava longe de ser a idealizada por seus praticantes, pois, em outra chave de interpretação, uma das imagens simbólicas da ciência da linguagem, para um público que não a praticava, negava sua validade, como parece nos indicar Carlos Drummond de Andrade, revelando um lugar paradoxal para a linguística: se por um lado a visão que os linguistas tinham de si mesmos conduzia a uma trilha positiva para o lugar do cientista da linguagem na sociedade, os versos do poeta, em 1976, colocavam em dúvida a validade da linguística como conhecimento sobre a língua.

3 "A partir dos anos setenta, a Lingüística e suas disciplinas passariam rapidamente a constituir um domínio específico e autônomo de investigação e despertariam um interesse e uma procura maior da parte dos pós-graduandos do que a Filologia. Em termos institucionais, sócio-profissionais e teórico-metodológicos, os anos setenta seriam dos linguistas" (ALTMAN, 1998, p. 125).

4 "A Lingüística Brasileira dos anos setenta reivindicou para si - e para mais ninguém - o estatuto de cientificidade em matéria de linguagem, em nome dos aspectos quantitativos, formal e rigoroso que dizia (e procurava) imprimir aos seus procedimentos" (ALTMAN, 1998, p. 278). 
$[\cdots]$

Da semia

Do sema, do semema, do semantema

Do lexema

Do classema, do mema, do sentema

Libera nos, Domine

$[\ldots]$

Da lingüística frástica e transfrástica

Do signo cinésico, do signo icônico e do signo gestual

Da clitização pronominal obrigatória

Da glossemática

Libera nos, Domine
Da estrutura exo-semântica da

linguagem musical

Da totalidade sincrética do emissor

Da lingüística gerativo

transformacional

Do movimento transformacionalista

Libera nos, Domine

$[\ldots]$

(DRUMMOND DE ANDRADE, 1992,

p. 862-863)

Ora fator que nos conduzia à modernidade e à ciência, ora saber que distanciava a linguagem de seus usuários, a linguística brasileira da década de 1970 viu seus pesquisadores se dividirem em diferentes grupos. Discursos inflamados tiveram o efeito de aglutinar propostas em um conjunto coeso e homogêneo ou, ainda, levaram a rupturas entre os que se reconheciam membros de grupos que atuavam de formas divergentes. É nesse contexto que se inserem Eurico Back e Geraldo Mattos, com a sua LINGUísTicA construTURAL, divulgada e defendida sob insistente e afiada retórica de ruptura com o que se produzia em ciência linguística não só no Brasil como também na Europa e nos Estados Unidos ${ }^{5}$.

Este texto pretende analisar a presença da LINGUística conSTRUTURAL na história da linguística brasileira a partir da escrita de uma narrativa ${ }^{6}$ sobre um projeto específico de análise linguística, suas técnicas e procedimentos metodológicos, ao lado de uma interpretação a respeito de sua constituição social como grupo de especialidade com uma retórica específica ${ }^{7}$, que pro-

5 "O termo retórica pode parecer fora de lugar aqui, pois sugere vagamente uma tentativa de se reforçar um argumento apelando-se para as emoções e não para o intelecto. Mas não há dúvida de que essa é a única palavra que podemos usar, já que banimos o termo 'positivismo' e questionamos o absolutismo da prova 'científica'. Nela está implícita uma dose adequada de ceticismo e de dúvida com relação a qualquer descoberta científica reivindicada, sem que no entanto haja a sugestão de que a questão toda deva ser encarada como uma fraude" (ZIMAN, 1979, p. 47).

6 A construção dessa narrativa parte de direcionamentos da Historiografia Linguística, considerada da seguinte forma: "A historiografia linguística é o estudo interdisciplinar do curso evolutivo do conhecimento linguístico; ela engloba a descrição e a explicação, em termos de fatores intradisciplinares e extradisciplinares (cujo impacto pode ser 'positivo', i.e. estimulante, ou 'negativo', i.e. inibidores ou desestimulantes), de como o conhecimento linguístico, ou mais genericamente, o know-how linguístico foi obtido e implementado" (SWIGGERS, 2010, p. 2).

7 Uma dimensão social da observação historiográfica na linguística pode ser estabelecida, por exemplo, em torno da categoria de análise grupos de especialidade, passível de observação por uma análise que recupera processos organizadores dos grupos e também a retórica assumida (a partir da definição de um espaço social) por pesquisadores e intelectuais em busca de legitimidade acadêmica, profissional e/ou social. 
curou a inserção no ambiente acadêmico brasileiro na década de 1970 como um projeto de investigação linguística ${ }^{8}$.

Na primeira parte, há uma análise a respeito da presença da GRAMÁtICA CONSTRUTURAL, OU LINGUísticA CONSTRUTURAL, ou, ainda, CONSTRUTURALISMO, como uma proposta de investigação científica situada em um espaço social específico demarcado por sua temporalidade e circunscrição, para proceder à construção de uma narrativa historiográfica de caráter externo ${ }^{9}$. Em uma segunda parte deste texto, uma abordagem de caráter interno será realizada: coloca-se em pauta a análise sobre a constituição de teorias e procedimentos metodológicos elaborados especificamente para a descrição de fenômenos linguísticos. O posicionamento aqui adotado coloca em constante diálogo os parâmetros interno e externo da investigação historiográfica (ou dimensões social e teórica), seguindo, dessa forma, Bourdieu (2004, p. 21), para quem "é preciso escapar à alternativa de 'ciência pura', totalmente livre de qualquer necessidade social, e da 'ciência escrava', sujeita a todas as demandas político-econômicas".

\section{2. "Estamos À PROCURA DA VERDAdE CIENTíficA": O PROJETO DA LINGUísticA CONSTRUTURAL}

No início da década de 1970, na região sul do país, Eurico Back e Geraldo Mattos (professores do ensino universitário no Paraná e já autores de uma considerável quantidade de obras didáticas sobre a língua portuguesa) propuseram a formação de uma "nova" teoria gramatical ${ }^{10}$. Adotando uma retórica de ruptura, com formas discursivas e propostas metodológicas próprias na visão de seus autores, contra abordagens da língua baseadas na Gramática Tradicional, na Gramática Gerativo-Transformacional e no Estruturalismo, a LINGUísticA constRUTURAL, como seus autores denominavam a proposta, começou em torno da comunidade acadêmica da Pontifícia Universidade Católica do Paraná. Textos de apresentação da Gramática Construtural

8 Uma dimensão teórica da observação historiográfica na linguística, levando em conta a dinâmica interna de fatos e eventos dos estudos sobre a linguagem, pode tomar como unidade de análise programas de investigação, entendidos como propostas de descrição e análise de fenômenos linguísticos, tendo como base formulações teóricas e procedimentos metodológicos.

9 Ao enfoque externalista de uma historiografia interessa sobretudo o aspecto social como parte do processo histórico de formação e desenvolvimento de uma ciência ou área de saber e de suas práticas discursivas, revelando posicionamentos ideológicos, sociais e históricos, em torno do estabelecimento de retóricas (formas e tipos de discurso adotados) típicas de comunidades de pesquisadores e intelectuais

10 Geraldo Mattos foi aluno de Eurico Back, com quem estabeleceu profícua colaboração, muitas vezes marcada pela relação mestre-aluno, como se pode depreender do depoimento de Mattos em entrevista concedida a Suzete de Paula Bornatto (2011, p. 204, 212). 
da Língua Portuguesa, publicada em 1972, apontam-nos que o que gerou a obra de descrição gramatical foram "pesquisa[s] realizada[s] sob os auspícios da Faculdade de Filosofia, Ciências e Letras da Universidade Católica do Paraná", e também nos informam que Back e Mattos eram "membros da Equipe de Pesquisa Lingüística" da mesma faculdade, onde eram doutores e livres-docentes de linguística (Back) e de língua portuguesa (Mattos), além de titulares nas respectivas áreas.

Um Manifesto divulgado em 1973 por Back e Mattos, publicado no periódico Construtura, propunha em tom programático uma teoria e procedimentos metodológicos para a descrição e análise da língua portuguesa, que na verdade já haviam sido explicitados na publicação da gramática um ano antes ${ }^{11}$.
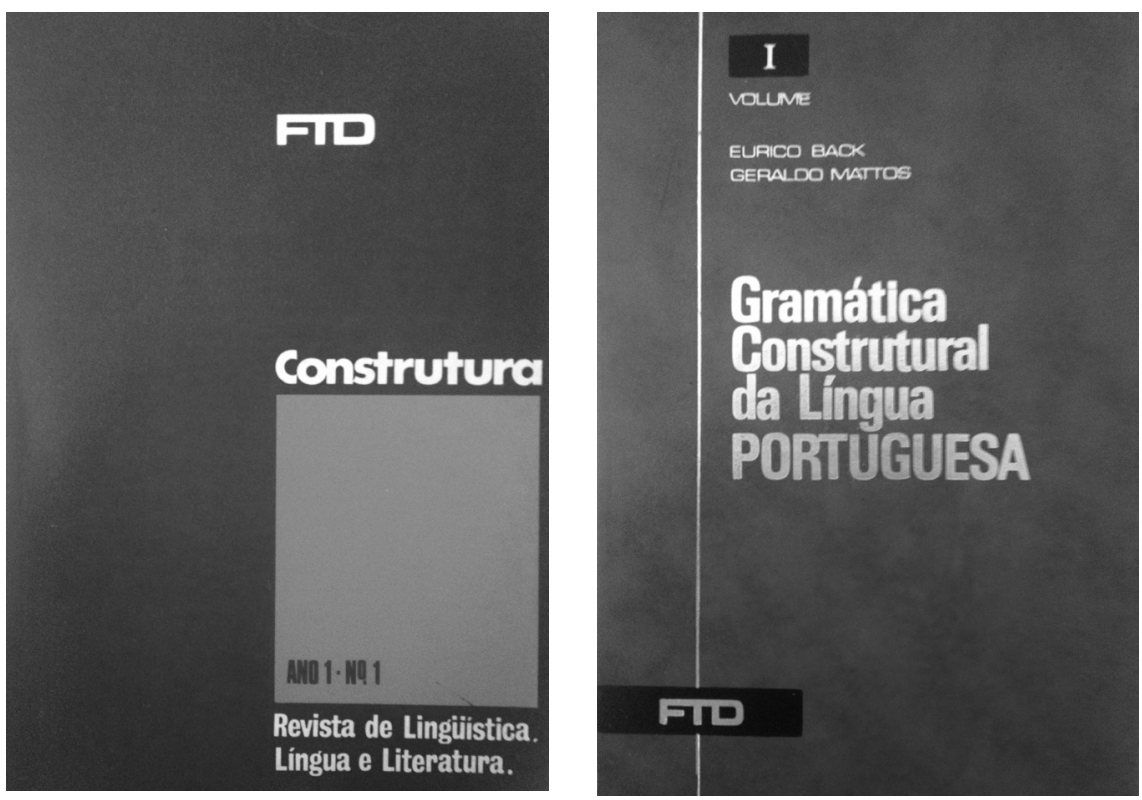

FIGURA 1 - IMAGENS DAS CAPAS DO PRIMEIRO NÚMERO DO PERIÓDICO CONSTRUTURA, QUE APRESENTOU EM 1973 O MANIFESTO DO PROGRAMA (À ESQUERDA), E DA GRAMÁTICA DE 1972 (À DIREITA).

FONTE: Fotografias tiradas pelo autor deste texto a partir dos exemplares originais. Acervo do autor deste texto.

Esse programa, entretanto, encontrou rejeição por grande parte dos grupos de especialidade que conformavam a linguística brasileira da época e que se reconheciam como membros de uma comunidade de produ-

11 O Manifesto é a publicação do primeiro número do periódico Construtura, pela editora FTD. De autoria de Back e Mattos o exemplar inaugural recebeu o título "Linguística Construtural manifesto", e em mais de cem páginas o que se encontrava era a apresentação teórico-metodológica do programa que eles propunham como distinto de outros. 
ção científica (cf. ALTMAN, 1998, p. 281). O depoimento abaixo, de um dos líderes da proposta construturalista - Geraldo Mattos -, deixa uma pista aberta para a percepção de que eles mesmos tinham conhecimento de que sua proposta era polêmica.

Uma coisa curiosa é que muitos dos nossos alunos foram fazer o mestrado em Campinas, na UNICAMP - o [nome de um ex-aluno] me falou que lá ele ouviu os professores dizerem: "nós não concordamos com a Construtural, mas uma coisa é certa - os alunos que vêm de lá, da Construtural, têm uma ideia muito melhor do que é a Linguística e vão bem em todas as disciplinas" (BORNATTO, 2011, p. 210).

Essa "negação" do movimento construturalista refletiu-se principalmente na ausência de continuidade das propostas, que no momento em que foram estabelecidas pareciam encontrar ventos mais favoráveis, considerando a presença de líderes intelectuais, Back e Mattos ${ }^{12}$, a publicação de um manual (a Gramática Construtural da língua portuguesa, em dois densos volumes pela FTD em 1972) e a proposição de um periódico publicado em cerca de dez volumes ao longo de mais de dez anos (a revista Construtura).

Revisões da história da linguística nacional mencionam o espaço ocupado pelo programa construturalista, visto de forma recorrente como uma proposta em torno da noção de inovação, ainda que esta seja de fato frequentemente questionada.

Em termos de teorias lingüísticas, nos primeiros anos, predominou o estruturalismo, seguindo modelos americanos como Bloomfield, Sapir e Pike, ou europeus como a Escola de Praga, Martinet, Pottier etc. Tivemos até um modelo teórico próprio, batizado como "lingüística construtural", proposto por Eurico Back e Geraldo Mattos, de Curitiba, divulgado na revista Construtura, e que teve como resultado de suas pesquisas uma Gramática Construtural da Língua Portuguesa (2 volumes), publicada em 1972 pela editora FTD, de São Paulo. A proposta construtural surgiu no momento da implantação dos cursos de pós-graduação, e não resistiu à concorrência do modelo gerativista que dominou a década de 70 , graças

12 Para Murray (1994), a formação de grupos de especialidade (theory groups) depende da presença de líderes intelectuais e organizacionais. No trecho a seguir, afirmação feita por Suzete de Paula Bornatto em pergunta para Carlos Alberto Faraco (BORNATTO, 2011, p. 219), pode nos direcionar para uma interpretação de que havia, sim, uma diferença no papel assumido por Mattos e Back na proposição e desenvolvimento do programa de investigação, em que um estaria mais vinculado a atividades criadoras e outro assumiria mais o papel de líder organizacional: "E essa parceria do Geraldo e do Eurico - porque o Geraldo, da perspectiva dele, era o mentor intelectual da coisa e o Eurico era quem fazia a coisa sair, organizava..." 
aos novos doutores que retornavam do exterior (A "LINGUÍSTICA NO BRASIL", Disponível em: <http://www.comciencia.br/reportagens/linguagem/ling15.htm>, Acesso em: 2/3/2014).

Nas páginas finais do manifesto de 1973 [...], Back e Mattos dispõem, em forma de lista, o que consideram as principais características do construturalismo (em oposição aos então chamados 'estruturalismo' e ao 'transformacionalismo'). [...] Seja como for, o fato é que o movimento foi proposto como original. Nascido no Paraná, longe, portanto, dos principais eixos de divulgação - Rio e São Paulo - mesmo assim conseguiu criar seus próprios meios de divulgação, o que parece reforçar a hipótese de que o sucesso na aceitação de um conjunto de idéias parece depender mais da capacidade dos seus organizadores de constituírem grupos e obterem commitment, do que do valor intrínseco dessas mesmas ideias. [...] é preciso lembrar que o construturalismo teve repercussão suficiente para manter um periódico durante vários anos, publicar uma gramática e também ser alvo de críticas [...], principal índice de seu efêmero sucesso (ALTMAN, 1998, p. 281).

Se partiram de um terreno em que influências iniciais eram reconhecidas, principalmente ancoradas em diferentes propostas do estruturalismo norte-americano de influência behaviorista, Back e Mattos fixaram a força de seu papel como líderes, ao apontar que propunham uma nova forma de descrição gramatical, deixando de lado, pelo menos no discurso que adotavam, as influências externas. No trecho abaixo, a retórica de ruptura se estabelece com as propostas da Tagmêmica, uma das vertentes do estruturalismo norte-americano.

A Linguística Construtural é resultado de quinze anos de pesquisas conjuntas, realizadas por Eurico Back e Geraldo Mattos. Ao início dos nossos trabalhos, consistia nosso intuito dotar a língua portuguesa de uma gramática científica em moldes tagmêmicos; contudo, à medida que avançávamos na pesquisa, sempre mais deficiente nos resultava o modelo tagmêmico e, inconscientemente talvez, começavam as inovações, trazidas pelo estudo exaustivo dos mecanismos da língua portuguesa. A certo momento, descobrimos que nos afastáramos enormemente do modelo tagmêmico e caminhávamos em novos terrenos. Optamos por interromper a pesquisa sobre a língua portuguesa e deter-nos com mais afinco na procura de um novo modelo, que incluísse as conquistas realizadas. E surgiu a Linguística Construtural (MATTOS, 1974, p. 22).

Só que nós começamos dentro da Tagmêmica de Pike [....], onde há construção e onde há estrutura, tá? Muito bem. Aí, de repente, 
lá na Federal -- eu nem estava lá ainda - eu disse pra ele: Eurico, veja uma coisa interessante - ó, aqui tá o Pike, a construção está num nível, porque no Pike também tem nível - morfema, vocábulo, locução, conjunto de locuções - que nós chamamos sentença - e a estrutura dele tá no outro nível - isso não tá certo. Pensa bem se não dá pra gente colocar: no vocábulo, há uma estrutura e há uma construção, depois na locução, há uma construção e há uma estrutura, e assim por diante - se nós fizermos isso, nós não estamos mais dentro da tagmêmica - rompemos com a tagmêmica. E como agora a construção e a estrutura estão no mesmo nível, não há o nível construção nem o nível estrutura, mas um nível duplo, que a gente pode chamar de construtura. O nome é meu. E isso resolveu, e deu certo. Mas depois ele foi pra Reitoria - e nosso estudo em conjunto morreu (BORNATTO, 2011, p. 213).

Em texto publicado na Revista Brasileira de Lingüística (1974) com o objetivo de apresentar o programa de investigação, o discurso adotado por Mattos ressaltava a busca pela cientificidade. A própria estrutura do artigo revela essa tentativa, com o cuidado da delimitação das propostas e da indicação da forma como a língua seria tratada. A retórica de Mattos criticava implicitamente a imagem de uma linguística nacional caracterizada pela recepção, manifestada sobretudo pela aplicação de teorias a dados do português, por exemplo. O construturalismo, por meio da retórica de seus líderes, pretendeu-se distante dessa imagem, clamando por ruptura, pois se viam perto de alcançar um nível teórico em seus estudos. Mais uma vez, o discurso de descontinuidade, se indicou uma primeira influência da Glossemática de Louis Hjelmslev, para depois abandoná-la (segundo eles mesmos), deixou de apontar que muito da proposta de uma linguística imanente norte-americana ainda estava presente no programa construturalista, a despeito de sua forte retórica de descontinuidade com as influências dos EUA. Entre os aspectos que permitem evidenciar esse diálogo estão o desejo de construir uma proposta científica, a nova metalinguagem para conceitos elaborados (pela qual a Glossemática ficou notoriamente reconhecida), a retórica de franca ruptura, a proposta de uma teoria que estuda relações de dependência entre elementos de um sistema, a exploração dos níveis de análise a partir de unidades maiores e complexas (o texto) e o tratamento do conteúdo e da expressão a partir de mesmos princípios ${ }^{13}$.

No Manifesto de 1973 (BACK; MATTOS, 1973, p. 115), a busca pelo "novo" caracterizava o ideal de teorização a que os construturalistas alme-

13 A avaliação que Francis Whitfield faz da Glossemática pode ser levada em conta na análise do construturalismo sem muito esforço: "A êsse respeito [retomada de aspectos tradicionais na teoria] - apesar da estranheza dos têrmos técnicos e apesar da pretensão inteiramente justificada de que propõe uma visão revolucionária da linguagem - a Glossemática é um dos tipos mais tradicionais de Linguística [...]" (WHITFIELD, 1974, p. 258). 
javam e difundiam por meio de uma retórica que definitivamente procurava lançar novas fronteiras e modos de atuação para a linguística nacional da época: "nova conceituação de sistema, significado e estilo e, consequentemente, nova apresentação do estudo dos significantes, da Semântica e da Estilística”.

Analisando a iniciativa de Back e Mattos pelo olhar da Historiografia Linguística, em uma análise da dimensão social da proposta dos construturalistas, diante de toda a retórica de ruptura adotada e também dos esforços de divulgar a teoria (por meio das diferentes publicações), é possível afirmar, inicialmente, que o grupo de especialidade da GRAMÁTICA CONSTRUTURAL não executou os passos necessários indicados por Murray (1994) para o estabelecimento de fato de um programa de investigação que pudesse ser reconhecido pela comunidade de linguistas como forma legítima de descrição da língua. Isso porque, nos passos da análise sociológica de Murray (1994), os líderes, Back e Mattos, não formaram aquela massa necessária de pesquisadores jovens para que as propostas se difundissem. 0 centro de proposição de uma teoria não pode se fechar nele mesmo. De seu centro, a formação de novos pesquisadores deve permitir que novos centros, distantes regionalmente até, sejam alcançados, fazendo, assim, com que os diálogos se estabeleçam e as trocas deem frutos, a partir do momento em que o grupo se vê diluído em subgrupos, com pesquisadores engajados na disseminação das propostas.

Nesse sentido, a proposta não teve repercussão suficiente para se tornar atuante na linguística brasileira, não conseguindo fazer frente ao grupo da Gramática Gerativa ${ }^{14}$, que cada vez mais aumentava seu poder de atração de novos e jovens pesquisadores, que trataram de divulgar e aplicar as propostas do grupo em centros de difusão científica importantes, principalmente situados no eixo sudeste, em grandes universidades de prestígio (cf. BATISTA, 2010). O construturalismo ficou marginal, fora das grandes universidades públicas da época, onde de fato se encontrava a grande concentração de financiamento que permitiu a formação de novos pesquisadores.

No entanto, é possível ainda, como faz Altman (1998, p. 281), apontar um relativo sucesso do grupo, considerando uma perspectiva regional (no Paraná, os autores e sua proposta são constantemente lembrados) e também as publicações da gramática e do periódico, assim como a reação ou negação a que o construturalismo foi submetido historicamente. O depoimento abaixo, de Carlos Alberto Faraco (que teve contato no Paraná com Back

14 o paralelo entre a Gramática Gerativa e a Gramática Construtural se dá no sentido de que as duas propostas firmaram de modo incisivo uma retórica de ruptura com formas de tratamento da linguagem que existiam no meio acadêmico brasileiro em décadas anteriores ao período que corresponde ao final dos anos sessenta e o desenrolar dos anos setenta. 
e Mattos), oferece uma perspectiva positiva para a presença do programa construturalista e seus líderes na história dos estudos sobre a linguagem:

[Bonatto]: E o que sobra da Construtura? Da iniciativa deles, no sentido do ensino de português?

[Carlos Alberto Faraco]: Acho que há duas coisas interessantes. Primeiro, a metodologia, a prática de análise a que eles deram o nome de Construtura. Quando eu fui pra Campinas, o Carlos Franchi uma vez, eu fui pra Campinas em 76, e o Borges foi em 78, então o Carlos Franchi disse, avaliando, "é impressionante a capacidade que vocês têm de análise de dados”. Isso era verdade, o Eurico tinha essa característica de nos formar linguistas que sabiam trabalhar com dados. O curso dele de linguística era isso. Então, a gramática e a ideia de uma análise, que nasceu da Tagmêmica, era uma extensão da Tagmêmica, tinha essa característica de lidar com o dado e obrigar metodologicamente a não arredar pé do dado. Era um poder bem do empiricismo, então isso acabou sendo fixado pra gente, nós sempre lidamos bem com os dados. Agora, do ponto de vista do ensino, o Eurico marcou uma época, embora você possa analisar criticamente o conjunto, os pressupostos que sustentavam a proposta dele, ele marcou uma época no sentido de colocar o domínio da linguagem como prioritário, esse ficou - apesar de os livros não circularem mais. (BONATTO, 2011, p. 218-219).

De qualquer modo, como já apontado em outros trabalhos (ALTMAN, 1998; BATISTA, 2011), uma proposta que partia de uma visão geral de língua como comunicação, apoiada numa visão behaviorista e mecanicista da língua, já não encontrava eco na comunidade de linguistas da década de 1970. As propostas de Noam Chomsky, no final dos anos 1960, ao instituir a noção de faculdade da linguagem, não abriam muito espaço, devido ao sucesso na comunidade acadêmica brasileira da época, para a presença de um projeto de investigação linguística diretamente relacionado a uma concepção de linguagem considerada por muitos como ultrapassada. Diante disso, a LINGUísTICA CONSTRUTURAL de Back e Mattos, podemos assim interpretar, já nascia incapaz de fazer frente à imagem que o programa gerativista estava implantando como novidade e cientificidade, como de fato nos aponta Altman:

Embora se lhes tenham reconhecido o mérito da tentativa [...], o modelo, enquanto tal, foi rejeitado pelo restante da comunidade acadêmica que o percebeu fortemente vinculado a princípios estruturalistas (tagmêmicos), incompatíveis com o novo ideal de cientificidade gerativista (chomskiano) que começava a entrar em evidência (ALTMAN, 1998, p. 281). 


\title{
3. "Língua É ESTOQue E ESTILO": o PRojETo CONSTRUTURALISTA
}

A retórica de ruptura do grupo de especialidade que propôs a GRAMÁTICA CONSTRUTURAL como projeto de investigação na linguística brasileira da década de 1970 insistiu em seus textos programáticos que estava configurando um "novo caminho" para a descrição e análise linguística de unidades e fenômenos da língua portuguesa. Esse novo caminho foi definido, em forma de itens, no Manifesto de 1973, com uma abertura que não deixava dúvidas para o tipo de discurso que seria adotado por Back e Mattos na defesa de seu projeto de investigação científica:

Antes de apresentarmos os princípios nos quais se baseia a doutrina construtural, é de se notar por que não nos filiamos a nenhuma das correntes existentes e por que propomos rumos novos e, por conseguinte, uma nova orientação, uma nova escola (BACK; MATTOS, 1973, p. 1).

Em especial, uma das manifestações discursivas de Back e Mattos chama a atenção: o texto de apresentação da gramática de 1972 .

\begin{abstract}
Abandonamos também a Gramática Transformativa, os Constituintes Imediatos (a Sintagmática), a Gramática Imanente, por não concordarmos com os seus postulados. O nosso estudo inicial nos levou a considerar a Tagmêmica o melhor modelo. Entretanto, no correr de nossas pesquisas, nem ela nos podia socorrer em todos os instantes e a técnica de Pike e Longacre não resolvia todos os casos (BACK; MATTOS, 1972, Introdução).
\end{abstract}

Reconheciam nesse trecho, como já apontamos, um diálogo inicial com escolas do estruturalismo norte-americano ${ }^{15}$, também de base descritivista, mas delas se desassociavam retoricamente. E retoricamente apenas, porque o que se observa no desenvolvimento do programa construturalista

15 "Na década de vinte, contudo, foi nas universidades dos Estados Unidos que a lingüística, especialmente o estudo descritivo, encontrou melhor acolhida. Acresce que a lingüística americana dos anos compreendidos entre a primeira e a segunda guerra mundial exerceu profunda e duradoura influência sobre o desenvolvimento dos estudos e do pensamento lingüísticos em todo o mundo" (ROBINS, 1983, p. 168).

"Mas é sobretudo depois de 1920 que, na lingüística estadunidense, vêm-se desenvolvendo características específicas com relação à lingüística européia. De um lado, temos a predominância da direção estruturalista (nos diferentes aspectos representados pelas concepções de Sapir e Bloomfield); de outro, no interior das colocações estruturalistas, temos a clara predominância dos interêsses sincrônicos sôbre os diacrônicos" (LEPSCHY, 1971, p. 79-80). 
é a manutenção de muitos elementos da Tagmêmica, enfraquecendo, desse modo, a proposta de inovação como queriam os construturalistas. Entre os pontos que ancoravam a Linguística construtural e que eram presentes no núcleo da Tagmêmica, cujo nome principal é o de seu fundador - Kenneth Pike -, estão os seguintes (cf. JONES, 1995): a) a consideração de uma teoria de caráter global, que estudasse desde os elementos sonoros até o uso linguístico; b) a proposição de uma unidade básica estrutural da linguagem que poderia ser considerada para análise nos diferentes níveis de descrição; c) a série de relações estruturais presentes também nos diferentes níveis de descrição; d) a noção de construção como base para compreensão das relações linguísticas; e) o rigor em notação de caráter formal.

Se os posicionamentos de Back e Mattos advogavam o lugar do inédito e do original, a prática de descrição e análise que eles empreenderam traiu o desejo de marcar um espaço inovador na linguística brasileira. Como já apontava Naro (1976), não há como negar a recriação que Back e Mattos fizeram de propostas presentes na ciência da linguagem há pelo menos algumas décadas antes do projeto construturalista.

Tendo como ponto de partida o enfoque tagmêmico, começaram fazendo ligeiras modificações e terminaram com um modelo que lhes pareceu suficientemente diferente da tagmêmica a ponto de merecer a nova denominação de "gramática construtural". [...] $\mathrm{Na}$ realidade, a gramática construtural em nada ultrapassa suas origens estruturais, consistindo apenas de um método essencialmente taxonômico de descrição lingüística (mais do que de explicação) estreitamente baseada na análise em constituintes imediatos. [...] mas em geral é conservada a maioria dos erros característicos do estruturalismo, inclusive a concepção behaviorista básica que considera a língua como reação a um estímulo (NARO, 1976, p. 95-96).

Em meio a uma expressiva retórica de descontinuidade, como apontamos, uma seção do Manifesto, chamada "paralinguagem", definia a base teórica do programa, apresentando suas principais linhas articuladoras: a abordagem do complexo de relações contraídas de modos diversos pelos elementos do código linguístico e os postulados assumidos pelo exame da comunicação -- função primordial da linguagem para os construturalistas. A partir da necessidade da troca verbal, diferentes relações determinariam formas de linguagem, descritas por meio de uma metalinguagem que, de fato, torna-se uma das peculiaridades mais notáveis da LINGUística ConstRuTURAL, com termos de alta carga metafórica. Como havíamos apontado, a Glossemática também ancorava na metalinguagem e em novos termos a sua retórica de novidade: se Back e Mattos falavam em "sol" e "planetas" para 
relações de dependência, Hjelmslev falava, para o mesmo tipo de relação, em “constelações” (cf. HJELMSLEV, 1975; LEPSCHY, 1971).

Toda estrutura [forma cujos elementos estão em dependência] é como o sistema solar: existe o sol [elemento condicionante da existência ou não de outros elementos], e possíveis planetas [elementos condicionados]; entretanto, o reconhecimento de planetas implica no reconhecimento da existência de um sol.

Existem, por conseguinte, estruturas de um só elemento: o sol. Exemplo de estrutura oracional do português, de um só elemento: Choveu. Portanto, a estrutura não é necessariamente binária; pode ainda ter três ou mais elementos. Exemplo de estrutura oracional do português com 4 elementos:

o guia mostrou a cidade aos turistas.

Planeta Sol Planeta Planeta

(BACK; MATTOS, 1973, p. 35-36).

Refletindo o ideal da época, em que a linguagem era vista como objeto de pesquisa à altura daqueles típicos das áreas com tradição em observação científica, a metalinguagem adotada pelos construturalistas utilizava o jogo metafórico e comparativo para transmitir ideias abstratas, estratégia comum a outras ciências. Ou seja, a metalinguagem também era motivada por uma tentativa de concretizar perspectivas mais abstratas de entender fenômenos da linguagem, concretizados então em uma gramática específica da língua portuguesa.

Temos um exemplo na relação entre casal e prole: a prole depende do casal, que é a condição necessária da prole; a prole não pode existir sem a existência do casal.

Outro exemplo é a relação entre objeto e predicado: o objeto depende do predicado, porque a presença do predicado é a condição necessária da presença do objeto; o objeto não pode existir sem o predicado (BACK; MATTOS, 1973, p. 5).

$\mathrm{Na}$ análise das relações estruturais que sustentavam a organização do sistema linguístico, segundo os construturalistas, ganhava relevo especial a construtura, que podia ser reconhecida em diferentes níveis de descrição linguística e suas unidades - do morfema às unidades concretas de comunicação -, sendo o termo derivado da junção de conSTRUção e ESTRUTURA. 
A construtura é uma forma em que os elementos estão em codependência e um deles é a construção e o outro é a sua estrutura. (Construtura $=$ construção e estrutura). A construção [alinhamentos e arranjos] é a parte permanente; a estrutura é a parte imanente. (BACK; MATTOS, 1973, p. 53)

Como se vê, a definição do termo central do programa levava em conta os conceitos de permanente e imanente: "imanente é o que se refere à organização do código, é o que está por dentro e não é percebido pelos estranhos. Permanente é o que pode ser percebido por aqueles que não conhecem as regras do jogo" (BACK; MATTOS, 1973, p. 40, grifo dos autores).

O sinal [signo linguístico] é, portanto, uma construtura de dois elementos coocorrentes: o significante, que é a permanência do sinal, e o significado, que é a imanência do sinal.

Sinal

$$
\begin{aligned}
& \text { Construtura --- } 10 . \text { elemento }=\text { significante }=\text { permanência } \\
& ---2 \text { 20. elemento }=\text { significado }=\text { imanência }(\text { BACK; } \\
& \text { MATTOS, 1973, p. 40). }
\end{aligned}
$$

o programa definia quatro pontos essenciais nos quais se assentavam suas propostas e que, consequentemente, estabeleciam objetos de investigação: a) as relações entre os elementos; b) a comunicação; c) 0 sinal; d) a linguagem.

As relações entre os elementos constituía o cerne da proposta da GRAMÁTICA CONSTRUTURAL, uma vez que o próprio termo CONSTRUTURA indiciava a formação de uma estrutura de relações de dependência, codependência, independência e interdependência (termos de longa tradição nas abordagens descritivistas) entre unidades linguísticas dos diferentes níveis de descrição.

Outro ponto essencial era a comunicação, considerada de um ponto de vista mecanicista. Ainda que o discurso construturalista tenha procurado distância dessa perspectiva da linguagem, é difícil negar a existência desse modo de encarar o processo comunicativo, sendo que, inclusive, em muitas passagens do Manifesto, há trechos em que a compreensão do processo de aquisição de linguagem é fundamentalmente construído na herança da teoria behaviorista, presença também em alguns projetos de investigação da linguística estruturalista norte-americana, como a Tagmêmica e o Distribucionalismo ${ }^{16}$. 
Os trechos abaixo permitem traçar uma tradição de pesquisa sobre a linguagem em torno dos pressupostos behavioristas. Mesmo que os autores da proposta construtural não tenham de fato explicitado a influência, o discurso assumido não nos deixa dúvida do diálogo entre as teorias.

A primeira característica da comunicação é a presença inevitável de um impulso que nos leva a agir, porque a inatividade é fundamental em todos os seres, ou, melhor que a inatividade, a permanência num determinado estado, tecnicamente chamado inércia. o impulso dá o necessário empenho para vencermos a inércia e mudarmos de estado.

O emissor sente um impulso (interno: o motivo, como a sede; ou externo: o incentivo, como um cartaz de refrigerante). Evidentemente, os motivos são extraordinariamente mais possantes que os incentivos: é mais fácil resistir a um cartaz de coca-cola do que à sensação de sede, língua e garganta secas.

O impulso contribui com os objetivos da comunicação: comunicamo-nos com alguém, empurrados por impulsos e os objetivos são os meios de alcançarmos a satisfação para esses impulsos. A fome é um impulso e o alimento é um objetivo; a chuva é um impulso e o guarda-chuva é um objetivo, ou uma marquise onde acolher-nos. Com ações reflexas, independentes da nossa vontade, ao impulso segue-se imediatamente a correspondente ação (BACK; MATTOS, 1973, p. 9, grifo dos autores).

A esta altura podemos entrosar os elementos da comunicação numa cadeia, num circuito de ação e reação, em que a presença de um determine o aparecimento de outro, para se tornarem claras as implicações entre eles. Esta cadeia permite a construção da célula comunicativa mínima: a cláusula. Como nos treinamos exaustivamente desde cedo, esta técnica tornou-se hábito e frequentemente deixamos de perceber todos os elementos envolvidos, com grave prejuízo para a efetividade de nossos objetivos.

A cláusula aparece dentro deste modelo:

\begin{tabular}{|c|l|l|l|l|}
\hline \multirow{3}{*}{ Cláusula } & Emissor & Impulso & Atividade cerebral & Texto proferido \\
\cline { 2 - 5 } & Receptor & Satisfação & Atividade cerebral & Texto percebido \\
\cline { 2 - 5 } & \multicolumn{2}{|c|}{ Situação } & \multicolumn{2}{|c|}{ Mensagem } \\
\hline
\end{tabular}

Precisemos o modelo!! Um emissor sente uma necessidade, interna ou externa (impulso para agir), ocorre-lhe uma série de "idéias" sobre como satisfazer a essa necessidade (atividade cerebral) e procura os recursos de atingir o receptor (texto); encerra-se a solicitação. Se chegar ao receptor por meio de algum canal, o

cularmente presente em Bloomfield, que submeteu o seu primeiro livro de lingüística, An introduction to linguistic science (Londres e Nova York, 1914), a uma profunda revisão, a fim de ajustá-lo ao ponto de vista mecanicista de estudiosos como A. P. Weiss, para quem as afirmações sobre as atividades e experiências humanas devem ser feitas apenas com base em fenômenos que podem ser observados por todo e qualquer indivíduo" (ROBINS, 1983, p. 168-169). 
enunciado provoca nele um conjunto de "idéias" complementares às do emissor e o leva a determinadas reações (satisfação); fecha-se o circuito, culminando num ato de comunicação (BACK; MATTOS, 1973, p. 11-12)

Algumas colocações de Bloomfield direcionam nossa interpretação para a presença - na LINGUísTICA CONSTRUTURAL - de um programa estruturalista de base descritiva, ancorado no behaviorismo ${ }^{17}$.

A psicologia especificamente nos fornece esta sequência: para um certo estímulo (A) uma pessoa reage falando; sua fala (B) por sua vez estimula seus ouvintes para certas reações (C). Por meio de um hábito social que cada pessoa adquire na infância pelo contato com adultos, A-B-C estão intimamente relacionados (BLOOMFIELD, 1958 , p. 26, tradução nossa) ${ }^{18}$.

Além das relações entre os elementos do código e o processo comunicativo, o projeto construturalista definia o que entendia por sinal. Nesse postulado, percebe-se de modo mais nítido uma visão de linguagem que conduz a uma correlação com a perspectiva adotada pelo behaviorismo.

Cultura é o conjunto de conhecimentos, hábitos, crenças, atividades, recursos, técnicas, pensamentos, sentimentos e intuições de um grupo social. Os elementos da cultura podem classificar-se em sensáveis e insensáveis. Sensáveis são os entes como animais, plantas, minerais, habitações, utensílios e vestuários: todos perceptíveis a algum dos nossos sentidos. Os insensáveis não são percebidos por nenhum dos cinco sentidos. Muitos resultam da organização do grupo e das relações dos seus indivíduos, como governo, religião e hábitos. Nestes se inclui a linguagem. A linguagem é um hábito que se transmite à criança; aprende-se a linguagem após inúmeras tentativas de longos anos, cheias de erro e correção: é um hábito imposto pelo grupo. Como hábito, constitui um elemento da cultura (BACK; MATTOS, 1973, p. 16, grifo dos autores).

17 Um depoimento na análise que Altman (1998) faz da linguística brasileira é esclarecedor em relação a uma influência de Bloomfield: "Eurico Back fez o curso e ficou famoso por ter sido o único capaz de ler Bloomfield de ponta a ponta. Não havia traduções e nem todos podiam ler em inglês. Mais tarde, Back reinventou a Linguística. Fez uma cópia da Tagmêmica e da psicolinguística behaviorista de Bloomfield. O 'construturalismo' nasceu dessas leituras” (ALTMAN, 1998, p. 117).

18 "Psychology, in particular, gives us this series: to certain stimuli (A) a person reacts by speaking; his speech (B) in turn stimulate his hearers to certain reactions (C). By a social habit wich every person acquires in infancy from his elders, A-B-C are closely correlated" (BLOOMFIELD, 1958, p. 26). 
Seguindo a tradicional divisão do signo em significante e significado, os construturalistas assumiam ser complexa uma definição de significado, visto, entre outras características, como adquirido por meio da formação de hábitos e de uma transmissão direta entre os comunicantes (posicionamento também adotado por escolas estruturalistas norte-americanas entre as décadas de 1930 e $1960^{19}$ ):

O significado..., bom, aqui já não há unanimidade; então, por enquanto, o significado é o segundo elemento, isto é, pelo menos, aceito por todos.

Diremos, por enquanto, que o significado é a mensagem, i.e., a tradução das necessidades do emissor ou a tradução da satisfação do receptor (BACK ; MATTOS, 1973, p. 17).

Aprendemos a linguagem, ouvindo determinados significantes aplicados a determinadas situações e seguidos de determinada satisfação: a cada novo emprego do mesmo significante corresponderá alguma situação parcialmente igual e, com isso, se enriquece sempre mais o significado (BACK; MATTOS, 1973, p. 19).

O último elemento abordado na "paralinguagem" é a linguagem. Nesse postulado, há a concepção de linguagem mais explicitada: código discreto de sinais que tinha como função essencial a comunicação (com seus "entes": comunicantes, signos, situações e assuntos).

Para Back e Mattos a linguagem era um sistema composto por unidades contraindo diferentes relações. Uma concepção estrutural ${ }^{20}$ de linguagem que colocava como função primordial desta a comunicação. Objetos de observação além daquelas formas geradas pelo sistema não eram privilegiados no projeto construturalista, que descartava os usuários e o contexto como elementos legítimos para a análise linguística. A definição de linguística dada pelos autores seguia esse pressuposto, a partir do qual, por exemplo, a pragmática era considerada não como ramo dos estudos linguísticos, mas como área em diálogo com o que tradicionalmente se entende como ciência da linguagem (que para os construturalistas era mais ampla, como se pode ver a seguir).

19 "O papel do significado na linguagem e a sua abordagem é um tema de pesquisa importante e aborrecido. A princípio, muitos lingüistas Americanos, em um impulse de forte rejeição da Gramática tradicional e influenciados por uma posição behaviorista um tanto extremada, encaravam o significado com suspeita" (HAMP, 1974, p. 255).

20 Não se emprega nessas passagens o adjetivo estrutural como relativo a um programa de investigação Estruturalista, ao qual, retoricamente, se opuseram Back e Mattos. Estrutural no emprego apontado se refere a formas de análise da língua que privilegiam o sistema, suas unidades e relações, sem correlação imediata a uma filosofia de tratamento da língua que imediatamente se insira em um programa definido como estruturalista. 
A Linguística se limita a estudar os sinais linguísticos e não leva em conta as formas de comunicação "extralinguística" embora possam acompanhar, reforçar ou mesmo substituir o diálogo (vocal) em determinados momentos (BACK; MATTOS, 1973, p. 26).

A Ciência da Linguagem abrange três campos:

Linguística, ou o estudo dos sinais linguísticos.

Crítica, ou o estudo da validade do sinal.

Pragmática, ou estudo das ações e reações dos comunicantes. (BACK; MATTOS, 1973, p. 27).

A concepção de linguagem adotada e a definição do campo de estudos situam a Linguística construtural de Back e Mattos naquele que Swiggers $(1981)^{21}$ chamou de programa descritivista na história dos estudos sobre a linguagem. Pertencem a esse programa teorias e modelos que trabalham a estrutura linguística como objeto autônomo, sem relações com aspectos psicológicos e/ou sociais (no sentido de que seriam essas relações que favoreceriam o entendimento de fatos linguísticos).

$\mathrm{Na}$ articulação do conceito de significado também visualizamos o que seria um programa descritivista, que não leva em consideração outros elementos que não os perceptíveis nas formas, funções e estruturas linguísticas.

Num desses defeitos recaem todos os trabalhos de Lingüística (Semântica) apresentados até hoje, embora contenham parcialmente a verdade.

Pretendemos aqui atacar o estudo do significado, partindo de sua origem, e chegar às oponências entre vocábulos, alcançando o seu destino, sem entrarmos nas idéiais [sic] que fervem na mente dos comunicantes, porque inacessível ao exame direto, sem tombarmos na arbitrariedade, comprovando cada uma das afirmações feitas, e sem operarmos viciosamente de vocábulo a vocábulo.

Afirmação nossa:

O significado é a associação entre o significante e uma situação cultural.

O fato que a experiência fica gravada no cérebro, é outra história, não negamos; mas a Lingüística não pode investigar o que se passa

21 "Em Swiggers (1981a, 1991a; cf. 2004), argumentei a favor do uso de um conjunto descritivo de quatro programas de investigação, que podemos discernir ao longo da história da linguística: o programa de correspondência (a linguagem é vista em sua correlação com o pensamento e a realidade); o programa descritivista (a linguagem é vista como constituída de entidades formais e funcionais e de relações que podem ser capturadas por uma abordagem descritiva), o programa sociocultural (a linguagem é vista em sua relação com strata sociais e com configurações socioculturais), e o programa de projeção (a linguagem é vista como constituída de 'distritos' que podem ser descritos em termos de um quadro de trabalho lógico-intensional ou lógico-extensional)” (SWIGGERS, 2010, p. 6). 
na nossa mente. A Lingüística lida com o significante, o conjunto de sons vocais, e com o significado, a associação entre o significante e uma situação cultural (BACK; MATTOS, 1973, p. 43-44).

O projeto de Back e Mattos, portanto, pretendia descrever e analisar exaustivamente as relações estruturais da língua, interiorizadas no "estoque", e utilizadas em diferentes variantes e situações, configurando uma descrição e análise que caracterizava a língua como estoque e estilo (este último presente no uso criativo da língua a partir de escolhas do emissor, com diferentes objetivos nos processos de comunicação).

O estoque lingüístico interiorizado é o mecanismo da língua: seus elementos, suas relações (tagmemas) e suas classes, o reconhecimento das constantes e dos variáveis; o trajeto semântico.

Esta intuição lingüística permite ao falante operar sobre a língua criativamente no seu idioleto, pela comutação e pela transformação. A intuição não abarca, porém, o conhecimento científico e a classificação dos elementos e das formas lingüísticas. Entretanto, é de se notar que existem variantes de estruturas e construções: uma vez que alcançou os elementos constantes de cada forma, pode facilmente constituir variantes novas pela alteração dos elementos variáveis. Mais ainda: entre os elementos constantes ocorrem elementos redundantes; pode o comunicante facilmente omitir um dos elementos redundantes sem prejuízo da mensagem (BACK; MATTOS, 1973, p. 96-97).

$\mathrm{Na}$ aprendizagem do domínio passivo da língua, o comunicante adquire um estoque de construturas, estruturas, construções e respectivas classes, com constâncias, variantes, redundâncias.

No domínio ativo, o comunicante recria as formas da língua ou por imitação (igualdade), ou por emprego de variantes possíveis (discurso) ou por originalidade estética (estilo) (BACK; MATTOS, 1973, p. 105).

\subsection{Uma "NOVA" LINGUística E SEUS NíveIS DE ANÁLISE}

Apoiados na premissa defendida por seus líderes, a de que "nenhuma escola ou corrente da Linguística Moderna conseguiu fazer uma descrição coerente de todos os fatos de uma língua" (BACK; MATTOS, 1973, p. 1), a retórica de ruptura da GRAMÁTICA CONSTRUTURAL insistia que os modelos teóricos e descritivos então atuantes adotavam pontos de partida equivocados ou 
procedimentos que não podiam oferecer uma visão abrangente de todos os fenômenos linguísticos, com isso advogavam a necessidade de "estabelecer a Linguística num corpo de doutrina global e coerente, sistematizando todos os fatos da linguagem" (BACK; MATTOS, 1973, p. 1).

Assumindo a inovação, já que os construturalistas afirmavam, como vimos, em seus discursos programáticos que "é de se notar por que não nos filiamos a nenhuma das correntes existentes" (BACK; MATTOS, 1973, p. 1), um dos pontos principais em que se apoiava a GRAMÁtICA CONSTRUTURAL era o fato de que, em meio a algumas escolas estruturalistas - que privilegiavam as unidades fonológicas e morfológicas - e a propostas gerativistas - que privilegiavam as construções sintáticas -, alcançava uma sistematização total e coerente "de todos os fatos da linguagem" (BACK; MATTOS, 1973, p. 1), descrevendo e analisando o que para Back e Mattos ainda não tinha sido suficientemente abordado na linguística da época: os significados, a criatividade e a "performance".

Desse modo, ao lado da Fonologia, Morfologia e Sintaxe, eles propunham destaque para a Semântica e a Estilística, já que "o significante sem o significado nada vale; o significado sem o significante não existe em linguagem; e a possibilidade que tem o falante de criar, produzir elocuções jamais ouvidas?" (BACK; MATTOS, 1973, p. 1)

A proposta definia um conjunto de postulados e procedimentos que seriam válidos para análise de todas as unidades que compunham, para eles, uma língua. Nesse sentido, advogavam indiretamente que não seria necessária nem científica a presença de metodologias diferentes para cada nível de descrição linguística. O mesmo procedimento deveria ser capaz de analisar tanto um morfema como uma escolha estilística, todos descritos por meio do modelo de constRUTURA.

Temos aqui as seguintes estruturas:

a) de período: /Quem chegou?/ (apenas o sol do período)

b) de locução: /aquele menino/ (planeta e sol da locução)

c) de vocábulo: /aquele/ (apenas o sol do vocábulo). (BACK; MATTOS, 1972, p. 38).

No estudo da cláusula, temos três partes:

1) Fonologia da cláusula: estuda os significantes mediatos que sustentam a construção lexical:

A cláusula é um alinhamento de sílabas, com juntura aberta entre fator e decorrente.

A sílaba é uma estrutura melódica de fonemas, entre os quais a vogal é o sol, e as consoantes são planetas.

o fonema é um alinhamento de fonias constantes, realizado por um ou mais alofones. 
2) A Morfologia da cláusula estuda o arranjo:

Cláusula simples = diálogo de uma só cláusula.

Cláusula composta = cláusulas interligadas.

Cláusulas aglomeradas = cláusulas em seqüência, sem marca lexical.

3) A Sintaxe de cláusula estuda a sua estrutura: fator e decorrente e a dependência entre as funções, assinaladas por ordem. A coesão gera cláusulas complexas; a promoção, cláusulas mínimas. Exemplificação:

obs.: A 1a. linha indicará a estrutura da cláusula, com o seu fator e o decorrente, quando existe. A $2 \mathrm{a}$. linha indica a construção da cláusula em seu arranjo. Construção e estrutura são englobadas na construtura (apenas que, nesta esquematização, não será indicada a fonologia das cláusulas: o seu alinhamento e a sua melodia).

"Mais alguma coisa?? | | Mais nada." (Sabino, 1962,11.)

Mais alguma coisa?? | Mais nada.

$\mathrm{F}$
$\mathrm{CP}$
$106)$.

O quadro a seguir reproduz figura criada pelos autores para a visualização do modelo proposto. Nele podemos verificar que Back e Mattos não pretenderam criar nem uma teoria fonológica, nem uma teoria morfológica, nem uma teoria sintática, mas uma teoria global, que ainda implicaria, na análise, a semântica e a estilística.

o ponto de partida da nossa pesquisa é o texto, se possível de máxima extensão e de máximos ambientes. Do texto, devemos deduzir o estoque em todos os níveis. E a própria análise nos revela os níveis com seus elementos e nos indica se o texto é suficiente para estabelecer o estoque. Para estabelecermos o texto, valemo-nos de dois nativos: pessoas que falem determinada linguagem desde a infância. Compete-nos registrar o diálogo mantido entre eles com todas as suas minúcias, ainda que divergentes. A garantia deste procedimento reside em que o texto nos apresentará dois discursos: a atividade linguística de cada um dos falantes; cada um dos discursos nos servirá de prova para a compreensão do outro, um nos permite testar o outro.

Na Semântica é preciso partir da mensagem; na Léxica, da cláusula, o elemento supremo, até o morfema, o menor elemento significativo, e até a fonia, o menor significante mediato, aplicando o modelo construtural: 


\begin{tabular}{|c|c|c|c|c|c|}
\hline \multirow{10}{*}{ Construtura } & \multirow{7}{*}{ Construção } & \multirow{4}{*}{ Melodia } & \multicolumn{2}{|c|}{ Alinhamento } & \multirow[t]{4}{*}{ Fonologia } \\
\hline & & & \multirow{3}{*}{ Prosódia } & Tonalidade & \\
\hline & & & & Intensidade & \\
\hline & & & & Quantidade & \\
\hline & & \multirow{3}{*}{ Arranjo } & \multicolumn{2}{|c|}{ Simplicidade } & \multirow[t]{3}{*}{ Morfologia } \\
\hline & & & \multicolumn{2}{|c|}{ Composição } & \\
\hline & & & \multicolumn{2}{|c|}{ Aglomeração } & \\
\hline & \multirow{3}{*}{ Estrutura } & \multicolumn{3}{|l|}{ Coesão } & \multirow[t]{3}{*}{ Sintaxe } \\
\hline & & \multicolumn{3}{|l|}{ Promoção } & \\
\hline & & \multicolumn{3}{|c|}{ Subordinação } & \\
\hline
\end{tabular}

(BACK; MATTOS, 1973, p. 101-102).

\subsection{Os MÉTODOS DE UMA PROPOSTA DESCRITIVISTA}

De acordo com a perspectiva de cientificidade que dominava os paradigmas de investigação que propunham uma linguística imanente, a GRAMÁTICA CONSTRUTURAL, em meio à constituição de seus procedimentos metodológicos, também se encaminhou para uma formalização na apresentação de dados e fenômenos que investigava e apresentava aos seus leitores - assim como faziam diferentes escolas estruturalistas norte-americanas entre as décadas de 1930 e $1970^{22}$.

Em algumas passagens da apresentação do projeto, é possível constatar que as ciências exatas não deixavam de ser modelo em busca do ideal do fazer científico que tanto as pesquisas linguísticas procuravam alcançar, como se quisessem de forma incisiva demarcar seu espaço distante daquele ocupado tradicionalmente pelas ciências humanas e pela Gramática Tradicional. A formalização, sem dúvida, na época adquiria um capital de valor simbólico (BOURDIEU, 2004) essencial para efetivar uma argumentação e persuadir prováveis adeptos de modelos e teorias.

Como a Matemática Moderna, admitimos conjuntos de 0, 1, 2 ou mais elementos. Exemplos: Em cantamos, a pessoa é um conjunto de 3 fonemas: mos /mux/; em cantais, é um conjunto de dois

22 "O resultado extremo de tais pontos de vista levou alguns estudiosos a rejeitarem a idéia de construir teorias gramaticais com finalidades explicativas, e a encararem a teoria lingüística francamente como um método para a reorganização dos dados. Obviamente, os estudiosos que compartilham dêste ponto de vista têm divergido consideravelmente no grau em que o aplicaram em seu trabalho. Mas aqui podemos encontrar a fonte da grande ênfase na técnica e no método de asserções compactas, que permeia grande parte do trabalho Americano; no formalismo meticuloso e na pureza das definições. Pensa-se freqüentemente que êsses hábitos de afirmações concisas e abstratas, e o gôsto pelos símbolos de aparência algébrica, que distinguem os lingüistas Americanos de seus colegas humanistas e a antropólogos, deriva de uma preocupação com a Matemática, a Lógica, ou, mais recentemente, com os computadores" (HAMP, 1974, p. 249). 
fonemas: - is, /yx/; em cantas, a segunda pessoa do singular é um conjunto de um só fonema -s; em canta, 3 a. pessoa do singular, a pessoa é indicada por ausência de fonemas: é um conjunto de zero fonemas (BACK; MATTOS, 1973, p. 5).

Inserida em uma tradição descritivista de estudos da linguagem, a LINGUística construtuRAL insistiu nos modelos matemáticos de formalização para a representação de fenômenos fonológicos, morfológicos, sintáticos, semânticos e estilísticos da língua portuguesa. Uma formalização e um apelo a uma linguagem que procuravam concretizar não só procedimentos metodológicos como também relações contraídas entre elementos linguísticos:

A relação de determinação grifa-se com uma flecha:

$$
\mathrm{A} \rightarrow \mathrm{B}
$$

Simplificando, adotamos apenas um parêntese: a ponta da flecha para representar essa mesma relação:

A) B

A leitura será: o elemento A depende do elemento B. A é revelador; B é relevado.

Dados dois elementos, o elemento A e o elemento B, diremos que o elemento A independe do elemento B quando entre ambos não houver nenhuma outra relação, salvo a de estarem dentro da mesma forma: nenhum revela a existência do outro.

Entre dois filhos temos uma relação de independência: nenhum deles depende do outro, nenhum deles tem o outro com qualquer relação, salvo a de estarem dentro da mesma forma (a prole).

O morfema /livru/ tem cinco elementos: nenhum deles depende de outro, mas todos estão contidos dentro da mesma forma (morfema). Assim, os cinco fonemas do morfema /livru/ são elementos independentes.

Assinalamos o elementos independente com o travessão:

$$
\mathrm{A}-\mathrm{B}
$$

E a leitura: o elemento A independe do elemento B (BACK ; MATTOS, 1973, p. 6-7).

O Manifesto de 1973 apresentava os procedimentos metodológicos, que se definiam em termos de práticas de descrição e análise linguística com a seguinte introdução: "quando afirmamos que obedecemos a uma técnica construtural para descrevermos a linguagem perfeita e integralmente, significamos que seguimos estas etapas de pesquisa" (BACK; MATTOS, 1973, p. 102).

As etapas da investigação científica a que se propunham os construturalistas partiam da observação da prática linguística entre falantes situados em determinados ambientes e situações, levando em conta também 
fatores circundantes que tornavam possível a troca verbal dos dois comunicantes, emissor e receptor. A partir dessa observação (que não era o foco principal, uma vez que o programa não considerava como legítimos para investigação elementos externos ao sistema), o texto (visto como veículo de informação) e suas mensagens eram examinados, ambos codependentes um do outro, na perspectiva de que a forma veicula um sentido. Constâncias (elementos que se repetem) e oponências (elementos que divergem entre si) eram observadas tanto no nível da materialidade (texto) quanto no nível da produção de significados (mensagem). Elementos da materialidade textual eram analisados por um "levantamento de cadeias sucessivas de oponências fônicas". Já em relação à mensagem eram observadas as "cadeias sucessivas de oponências significativas".

Feitos os levantamentos, era aplicado, como vimos, o modelo de construtura a diferentes níveis de análise, configurando a proposta de observar uma língua em todos os seus fatos e fenômenos, indo das unidades mais complexas de comunicação, e suas mensagens, até os componentes mais básicos da sonoridade (organizados em torno de arranjos e alinhamentos).

Rigor metodológico os construturalistas demonstraram. Um procedimento que, mais uma vez, estabelecia um diálogo, inconfesso no discurso dos brasileiros, com correntes da linguística estruturalista norte-americana:

Primeiramente, descobre-se que tipos de elementos a língua possui; êsses elementos são descobertos e definidos por meio de relações simples entre êles. Sòmente depois de feito isto é que se descreve a substância dêsses elementos puramente formais.

A Glossemática aceita essa consequência [analisar primeiro unidades mais complexas para depois chegar a unidades mais simples], começando sempre com a unidade maior possível - o texto inteiro, falado ou escrito, que toma como objeto de estudo imediato - e, pelos métodos já descritos, vai progressivamente analisando-o em unidades cada vez menores (WHITFIELD, 1974, p. 262-263).

\section{Conclusão: "novos" posicionamentos, "NOVAs" Conceituações E CONSEQUENTEMENTE...}

A narrativa historiográfica deve pretender expor fatos que se desenrolaram em um recorte temporal para, na sequência, alcançar outro nível de elaboração, que procurará estabelecer hipóteses explicativas para interpretar por que uma forma de conhecimento foi proposta em determinado contexto 
histórico-social. Cabe, portanto, ao historiógrafo "estabelecer relações causais entre os acontecimentos, para se compreender por que motivo as coisas se passaram como se passaram" (KRAGH, 2001, p. 70).

Este texto foi escrito em consonância com esses posicionamentos, colocando em ação uma abordagem de caráter externo e outra de caráter interno, pois a revisão da proposta construturalista e sua presença na linguística brasileira foi considerada em duas perspectivas: a) como projeto de investigação, o conSTRUTURALISMo se caracterizou por seu tratamento descritivista de estruturas e fatos linguísticos considerados em sua integralidade, a partir de uma teoria e um método que seriam capazes de descrever todas as manifestações da linguagem em seus diferentes níveis de análise; b) como manifestação de um grupo de especialidade, o construturalismo se caracterizou por sua marcante retórica de ruptura, clamando pela descontinuidade em relação ao que se conhecia como modelos de descrição e análise linguística.

o posicionamento discursivo adotado por Back e Mattos e suas escolhas teórico-metodológicas não se revelaram eficazes para o estabelecimento de uma forma de tratamento da linguagem, pois o projeto construturalista se perdeu em termos de continuidade histórica, tendo ficado confinado a um período específico em que seus propositores atuaram de modo mais incisivo. Faltou aos construturalistas um lugar na história da linguística brasileira de sua época que se mostrasse com solução de continuidade.

De fato, a ciência não é exatamente o locus da neutralidade e objetividade que o senso comum lhe atribui, mas uma dimensão em que posicionamentos sociais e resultados efetivos devem essencialmente ganhar o reconhecimento de pares para que encontrem um papel ativo na construção de uma ciência em suas diferentes vertentes. O conhecimento, assim, não é apenas representação de uma proposta teórica e metodologicamente construída, mas é também comportamento e forma de ação apta a articular socialmente modelos científicos em meio a diferentes projetos e construções teóricas, capazes, então, de validar propostas de tratamento da língua e seus fenômenos.

Enfim, não bastaria, no curso histórico dos saberes e do conhecimento linguístico, dizer apenas, mas fazer, isto é, imprimir uma imagem positiva e duradoura que sustente o reconhecimento científico. Nessa via de interpretação, deveria haver uma correspondência entre a proposição de ideias e métodos e os anseios (mesmo que de caráter mais abstrato e poucas vezes apreensível) de toda uma geração de pesquisadores, exatamente como Thomas Mann escrevia em Morte em Veneza:

Para que qualquer produto intelectual de peso possa surtir de imediato um efeito amplo e profundo, é preciso que haja uma afinidade secreta, uma coincidência entre o destino pessoal de seu autor e o destino anônimo de sua geração (MANN, 1991, p. 18). 


\section{REFERÊNCIAS}

A LINGÜÍSTICA NO BRASIL Disponível em: < http://www.comciencia.br/reportagens/linguagem/ ling15.htm > . Acesso em: 2/3/2014

ALTMAN, Cristina. A pesquisa linguística no Brasil (1968-1988). São Paulo: Humanitas, 1998.

BACK, Eurico; MATTOS, Geraldo. Construtura. Revista de Linguística, Lingua e Literatura, Curitiba, ano 1, n. 1, mar. 1973.

. Gramática construtural da Língua Portuguesa. 2 v. São Paulo: FTD, 1972.

BATISTA, Ronaldo de Oliveira. Em busca de uma história a ser contada: a recepção brasileira à Gramática Gerativa. Revista da Anpoll, São Paulo, v. 1, n. 29, p. 260-291, jan./jun. 2010.

. Aceitar ou negar as propostas da Gramática Construtural: uma interpretação historiográfica e sociológica de um período da gramática brasileira. In: CONGRESSO INTERNACIONAL DA ABRALIN, 7., 2011, Curitiba. Anais... p. 3777-3790. Disponível em: <http://www.abralin. org/abralin11_cdrom/artigos/Ronaldo_Batista.PDF>. Acesso em: 2/1/2013.

BLOOMFIELD, Leonard. A Set of Postulates for the Science of Language. In: JOOS, Martin (Ed.). Reading in Linguistics. 2nd. ed. New York: American Council of Learned Societies, 1958. p. 26-31.

BORNATTO, Suzete de Paula. A tradição e os singulares - o ensino de português proposto em livros didáticos por professores universitários do Paraná (1944 a 1980). 238f. Tese (Doutorado em Educação) - Programa de Pós-Graduação, Universidade Federal do Paraná, Curitiba, 2011. Disponível em: <http://www.ppge.ufpr.br/teses/teses/D11_bornatto.pdf>. Acesso em: 3/1/2013.

BOURDIEU, Pierre. Os usos sociais da ciência. Tradução: Denice Barbara Catani. São Paulo: Unesp, 2004. (Conferência e debate organizados em março de 1997).

COSERIU, Eugenio. Perspectivas gerais. In: NARO, Anthony J. (Org.). Tendências atuais da linguística e da filologia no Brasil. Rio de Janeiro: Francisco Alves, 1976. p. 11-44.

DRUMMOND DE ANDRADE, Carlos. Poesia e prosa. Rio de Janeiro: Nova Aguilar, 1992. p. 862.

DUBOIS, Jean et al. Dicionário de linguística. 5. ed. São Paulo: Cultrix, 1995. (1. ed. brasileira de 1973).

HAMP, Eric P. Escolas americanas de linguística. In: HILL, Archibald A. (Org.). Aspectos da lingüística moderna. 2. ed. Tradução: A. Pimentel Palácio et al. do original norte-americano de 1968. São Paulo: Cultrix, 1974. p. 246-256.

HJELMSLEV, Louis. Prolegômenos a uma teoria da linguagem. Tradução: Teixeira Coelho Neto do original inglês de 1961. São Paulo: Perspectiva, 1975.

HILL, Archibald A. (Org.). Aspectos da lingüística moderna. 2. ed. Tradução: A. Pimentel Palácio et al. do original norte-americano de 1968. São Paulo: Cultrix, 1974.

JONES, Linda K. Tagmemics. In: KOERNER, E. F. K.; ASHER, R. E. (Eds.). Concise History of the Language Sciences. Oxford: Pergamon, 1995. p. 314-319.

JOSEPH, John; LOVE, Nigel; TAYLOR, Talbot. Landmarks in Linguistic Thought II: The Western Tradition in the Twentieth Century. London: Routledge, 2001.

KOERNER, Konrad. Linguistic Historiography: projects and prospects. Amsterdam: John Benjamins, 1999.

KRAGH, Helge. Introdução à Historiografia da Ciência. Tradução: Carlos Babo do original inglês de 1987. Porto: Porto Editora, 2001.

LEPSCHY, Giulio. A lingüística estrutural. Tradução: N. Feres do original italiano de 1966. São Paulo: Edusp: Perspectiva, 1971. 
MALMBERG, Bertil. A língua e o homem: introdução aos problemas gerais da linguística. Tradução: M. Lopes do original sueco de 1970 e comparada com a tradução em espanhol. Rio de Janeiro: Nórdica: Livraria Duas Cidades, 1976.

MANN, Thomas. Morte em Veneza. São Paulo: Círculo do Livro, 1991.

MATTOS, Geraldo. A linguística construtural. Revista Brasileira de Linguística, São Paulo, n. 1, p. 22-39, 1974.

MOTOYAMA, Shozo; QUEIROZ, Francisco A.; VARGAS, Milton. 1964-1985: sob o signo do desenvolvimentismo. In: MOTOYOMA, Shozo (Org.). Prelúdio para uma história: ciência e tecnologia no Brasil. São Paulo: Edusp, 2004.

MURRAY, Stephen. Theory groups and the Study of Language in North America. A social history. Amsterdam: John Benjamins, 1994.

NARO, Anthony J. (Org.). Tendências atuais da linguística e da filologia no Brasil. Rio de Janeiro: Francisco Alves, 1976.

NARO, Anthony J. Tendências atuais da linguística e da filologia no Brasil. In: (Org.). Tendências atuais da linguística e da filologia no Brasil. Rio de Janeiro: Francisco Alves, 1976. p. 67-114.

ORTIZ, Renato. Cultura brasileira e identidade nacional. 5. ed. São Paulo: Brasiliense, 2006.

OS PENSADORES. Saussure, Jakobson, Hjelmslev, Chomsky. Textos selecionados. Tradução: Carlos Vogt et al. São Paulo: Abril Cultural, 1978.

PILAGALLO, Oscar. A história do Brasil no século 20 (1960-1980). 2. ed. São Paulo: Publifolha, 2009.

ROBINS, R. H. Pequena história da lingüística. Tradução: L. Barros do original inglês de 1967. Rio de Janeiro: Ao Livro Técnico, 1983.

SALUM, Isaac Nicolau. Prefácio à edição brasileira. In: SAUSSURE, Ferdinand. Curso de linguística geral. 17. ed. São Paulo: Cultrix, 1993. (1. a edição brasileira publicada em 1969).

SKINNER, Burrhus Frederic. O comportamento verbal. São Paulo: Cultrix, 1978.

SWIGGERS, Pierre. The History Writing of Linguistics: a methodological note. General Linguistics, v. 21, n. 1, p. 11-16, 1981.

História e Historiografia da Linguística: status, modelos e classificações. Revista Eutomia, ano III, v. 2, p, 2-17, dez./2010. Disponível em: <http://www.revistaeutomia.com.br/ volumes/Ano3-Volume2/especial-destaques/destaques-linguistica/destaque_history_and_historiography_of_linguistics.pdf>. Acesso em: 3/1/2013.

WHITFIELD, Francis J. A Glossemática. In: HILL, Archibald A. (Org.). Aspectos da lingüística moderna. 2. ed. Tradução: A. Pimentel Palácio et al. do original norte-americano de 1968. São Paulo: Cultrix, 1974. p. 257-265.

ZIMAN, John. $O$ conhecimento público. Tradução: Regina Regis Junqueira do original inglês Public Knowledge de 1968. Belo Horizonte: Itatiaia; São Paulo: Editora da Universidade de São Paulo, 1979.

Submetido em: 23/05/2013

Aceito em: 02/07/2013 